9 Kat\% FE, Ball L, Gibbons B, Chessells JM. The use of DNA probes to monitor minimal residual disease in childhood acute lymphoblastic monitor minimal residual disease in

10 Fey MF, Kulosik AE, Hansen-Hagge TE, Tobler A. The polymerase chain reaction: a new tool for the detection of minimal residual disease in haematological malignancies. Eur $\mathcal{F}$ Cancer 1989;27:89-93.

11 Deane $M$, Norton JD. Immunoglobulin gene 'fingerprinting': an approach to analysis of $\mathrm{B}$ lymphoid clonality in lymphoproliferative disorders. $\mathrm{Br}$ f Haematol 1991;77:274-81.

12 Yamada M, Hudson S, Tournay $O$, et al. Detection of minimal disease in hematopoietic malignancies of the $B$ lineage by using third-complimentaritydetermining region (CDR-III) specific probes. Proc Natl Acad Sci USA 1989;86:5123-7.

13 Briscoe MJ, Tan LW, Osborn AM, Morley AA. Development of a highly sensitive assay, based on the polymerase chain reaction for rare $\mathrm{B}$ lymphocyt

14 Beishuizen A, Hahlen K, Hagemeijer A, et al. Multiple rearranged immunoglobulin genes in childhood acute lymphoblastic leukemia of precursor globulin genes in childhood acute ly

15 Boehm TLJ, Werle A, Ganser A, Korhuber B, Drahovsky D. T cell receptor gamma chain variable gene rearrangements in acute lymphoblastic leukemias of T and B lineage. Eur $\mathcal{F}$ Immunol 1987;17:1593-7.

16 Gonsalez-Sarmiento R, Greenberg JM, Kersey JH. Use of gamma chain variable regions in human acute lymphoblastic leukemia. Blood 1988;72: $2038-41$.

17 Taylor JJ, Rowe D, Williamson IK, Christmas SE, Proctor SJ, Middleton $\mathrm{PG}$. Detection of $\mathrm{I}$-cell receptor gamma chain $\mathrm{V}$ region gene rearrangements using the polymerase chain reaction: application to the study of clonal disease cells in acute lymphoblastic leukemia. Blood 1991;77: 1989-95.

18 Tkachuk DC, Griesser H, Takihara Y, et al. Rearrangement of T cell delta locus in lymphoproliferative disorders. Blood 1988;72:353-7.
19 Yokota S, Hansen-Hagge TE, Ludwig W-D, et al. Use of polymerase chain reactions to monitor minimal residual disease in acute lymphoblastic reactions to monitor minimal residual

20 Kursrock R, Gutterman JU, Talpaz M. The molecular genetics of Philadelphia chromosome-positive leukemias. $N$ Engl f Med 1988;319:990-8.

21 Kawasaki ES, Clark SS, Coyne MY, et al. Diagnosis of chronic myeloid and acute lymphoblastic leukemias by detection of leukemia-specific mRNA sequences amplified in vitro. Proc Natl Acad Sci USA 1988;85:5698-702.

22 Kohler S, Galili N, Sklar JL, Donlon TA, Blume KG, Cleary ML. Expression of bcr-abl fusion transcripts following bone marrow transplantation for Philadelphia chromosome positive leukemia. Leukemia 1990;4:541-7.

23 Maurer J, Janssen JWG, Thiel E, et al. Detection of chimeric bcr-abl genes in acute lymphoblastic leukaemia by the polymerase chain reaction. Lancet 1991;337:1055-8.

24 Hunger SP, Galili N, Carroll AJ, Crist WH, Link MP, Cleary ML. The $t(1 ; 19)(q 23 ; p 13)$ results in consistent fusion of E2A and PBX1 coding sequences in acute lymphoblastic leukemias. Blood 1991;77:687-693.

25 Lee M-S, Chang K-S, Cabanillas F, Freireich EJ, Trujillo JM, Stass SA. Detection of minimal residual cells carrying the $t(14 ; 18)$ by DNA sequence aetection of minimal residual cells car

26 Biondi A, Rambaldi A, Alcalay $M$, et al. RAR alpha gene rearrangements as a genetic marker for diagnosis and monitoring in acute promyelocytic genetic marker for diagnosis and
leukemia. Blood 1991;77:1418-22.

27 Trask B. Fluorescence in situ hybridisation. Trends in Genetics 1991;7: 149-54.

28 Poddighe PJ, Moesker O, Smeets D, Awwad BH, Ramaekers FCS, Hopman AHN. Interphase cytogenetics of hematological cancer: comparison of classical karyotyping and in situ hybridisation using a panel of eleven chromosome-specific probes. Cancer Res 1991;51:1959-67.

29 Anastasi J, Thangavelu M, Vardiman JW, et al. Interphase cytogenetic analysis detects minimal residual disease in a case of acute lymphoblastic leukemia and resolves the question of origin of relapse after allogeneic bone marrow transplantation. Blood 1991;77:1087-91.

\title{
Stressful life events and childhood illness
}

An undesirable life event is defined as an adverse social experience with an identifiable onset, circumscribed course, and discernible end point, such as a death or permanent separation, the effects of which are likely to have an impact on an individual lasting more than a few hours. In other words, exposure to the adversity is relatively brief (hours or days) but the impact is substantive. Undesirable life events constitute a subclass of all types of life events (desirable, undesirable, and neutral) and one form of environmental experience that children are exposed to in everyday life. Ongoing difficulties are another form of social adversity, and refer to those social experiences where beginnings and endings are difficult to discern but indicate that a child is continuously being exposed to an undesirable experience, such as chronic marital disharmony, whose intensity and impact may wax and wane over time. For nearly 50 years life events and ongoing difficulties have been the subject of extensive research as potential causes of mental and physical disorders in individuals of all ages. It is only relatively recently, however, that different forms of life experiences to which children may be exposed have been the subject of classification and detailed research.

\section{Life events measurement}

Questionnaires have been developed for parents and children to indicate the number of events that have occurred over a defined time period, often the previous 12 months. Events have invariably been weighted for likely stressful effects. ${ }^{2} 3$ A grading of the 'stressfulness' of events such as parental death, divorce, personal illness, house or school move is then obtained. Unfortunately, there are considerable methodological problems with the measurement of life events by this procedure. Firstly, questionnaires invariably fail to cover all forms of recent life experiences; secondly, the wording of events is often ambiguous; thirdly, they cannot take into account the personal nature and qualities of events for children in different social and physical circumstances; and fourthly, they fail to determine when events occurred in relation to the onset or change (for example relapse or recovery) in the nature or course of disorder under investigation. To interpret the meaning of life events considerable effort should be expended in establishing the exact nature of the event and its temporal relationship with the episode (or change) of the illness.

Many of these methodological difficulties are overcome by using face to face interviews with parents and children. ${ }^{4}$ Interview procedures provide a more sensitive method for determining the prevalence of events as well as collecting detailed personal information about the event (who was involved, its nature, salience to the individual, duration, and outcome). Such information allows a judgment to be made on the likely impact of an event on the child knowing its full nature and circumstances. This also takes into account the appreciable individual differences that occur in children's social circumstances even for so called identical events such as death of a parent. Ratings of the degree of undesirability of any event can be obtained from a number of sources including parents, child, interviewer, or another professional not involved in the collection of the life event data. In addition, the onset of events can be carefully noted and compared with the onset of disorder being investigated. These methodological and procedural advances have resulted in a much greater understanding of the causal role of recent undesirable life events in the onset and recovery of anxious and depressive disorders in school age children. ${ }^{5-7}$

\section{Recent undesirable events and child psychiatric disorder}

There is now considerable evidence to show that most children between the ages of eight and 16 experience between three and five life events per year. Desirable events appear to occur with equal frequency in psychiatric cases and controls. ${ }^{8}$ There is, however, a significantly greater exposure to undesirable life events in the 12 months before the onset of psychiatric disorders in school age children compared with controls. ${ }^{5}$ It is apparent, however, that undesirable events are neither necessary nor sufficient as causal factors in all cases of psychiatric disorder. Indeed, when they occur in isolation there are significant but modest increases in the risk, approximately fivefold, for the occurrence of anxious and depressive disorders. For the majority 
of childhood emotional disorders (perhaps $75 \%$ ), however, undesirable events occur in combination with more ongoing difficulties such as distress and loneliness in mothers. Under these circumstances the risks of an episode of anxiety or depression are cumulative and may increase to as much as a hundredfold (as a consequence of multiplying together the known risks carried by each adverse experience) over children who are not exposed to this pattern of social adversities. ${ }^{9}$ Cumulative effects are not however always as straight forward as they appear. For example an absence of desirable events in a child's life carries no increase in risk for anxiety or depression. If a child concurrently experiences friendship difficulties, however, then there is an appreciable increase in risk (tenfold or more) as a result of the interaction between the two circumstances. ${ }^{8}$ In other words, no desirable events carries a latent enhancing effect which is activated only in the presence of a particular type of other social stressor. For example, no desirable events has no such latent effect in the presence of family focused life events. There are clearly a number of somewhat different psychological mechanisms that determine the effects of the environment on children's mental well being and development. ${ }^{1011}$ It has become apparent that we can no longer think of stress as an amorphous burden exerting rather nonspecific mechanical effects on children's lives. Rather, we must begin to determine the specific associations between different patterns of social adversity and types of psychopathology at different ages and stages of development. It is also clear from numerous studies on children at risk that exposure to events and difficulties even in combination does not inevitable result in psychiatric disorder. In other words, some children show resilience in the face of social adversities. ${ }^{1012}$ Determining what constitutes resilience to undesirable life events is an important area for further research.

\section{Stressful experiences and physical illness}

As yet there are no reported studies using life event interview methods to investigate the role of stressful life events in the onset, maintenance, or relapse of physical illness in children. There has, however, been considerable research on children with physical disease using life event questionnaires. Thus diabetes, juvenile rheumatoid arthritis, Crohn's disease, ulcerative colitis, and haemophiliac bleeds are disorders in which an excess of stressful events have been noted, compared with controls. ${ }^{13-16}$ In all of these studies no distinction was made as to whether or not events preceded the onset of symptoms or, more parsimoniously, the onset of an identified episode of the disease. It is unclear, therefore, if undesirable events precede the onset of episodes of these disorders, or that children with these disorders are more likely to experience undesirable life events.

One of the earliest and most seminal of studies on physical health in children was that of Meyer and Haggerty who followed up 100 children from 16 families prospectively over 12 months, undertaking throat cultures for streptococci every two weeks and having the family keep a diary of upsetting events that had occurred over the time period between throat cultures. ${ }^{17}$ Approximately a quarter of streptococcal infections suffered by the children were preceded by upsetting events of varying kinds. The findings allowed the authors reasonably to conclude that, for a significant proportion of children, stressful life events were potential causal agents in the onset of their infections.
Overall these research findings, together with much clinical experience, point to an important, but as yet undetermined role, for social adversities on the risk for relapse and recovery form physical illnesses. It remains much less clear if life events and difficulties contribute to the onset (that is the cause) of such illnesses.

What is currently needed are two different but complementary studies. Firstly, a prospective longitudinal study of a clinical population which systematically and concurrently documents the ebb and flow of physical illness, mood and behaviour, and changes in the environment. A study of this nature would provide repeated measures of life events and difficulties, and the physiological and behavioural state of the patient. Such a study would be able to determine the direction of effects between the environment and the child's physical and mental state. In addition, important information would be provided concerning which children were most likely to relapse as a consequence of environmental difficulties.

Secondly, an epidemiological longitudinal study in which well children at high risk for physical disease are screened and followed up until an illness develops. This would ensure the precise measurement of events, psychiatric status, and physical health before the onset of disease and determine their precedence to each other. Such approaches would provide much needed information on the role of environmental mechanisms and processes in the onset, maintenance, and outcome of physical diseases.

Section of Developmental Psychiatry,

IAN M GOODYER

Douglas House,

18 Trumpington Road,

Cambridge

1 Goodyer IM. Life Experiences, development and childhood psychopathologv. Chichester: John Wiley, 1990.

2 Coddington DR. The significance of life events as aetiologic factors in diseases of children-I. I Psychosom Res 1972;16:7-18.

3 Coddington DR. The significance of life events as aetiologic factors in diseases of children-II. F Psychosom Res 1972;16:205-13.

4 Goodyer IM. Recent life events and psychiatric disorder in school age children. F Citild Psychol Psychiatry 1990;31:839-48.

5 Goodyer IM, Kolvin I, Gatzanis S. Recent undesirable life events and psychiatric disorder in childhood and adolescence. $B r \mathcal{F}$ Psychiatry 1985;147: 517-23.

6 Goodyer IM, Kolvin I, Gatzanis S. The impact of recent life events in psychiatric disorders of childhood and adolescence. Br $\mathcal{J}$ Psychiatry 1987;151: 179-85.

7 Goodyer IM, Germany E, Gowrusankur J, Altham PME. Social influences on the outcome of anxiety and depression in school-age children. $\mathrm{Br}, \mathcal{F}$ the outcome of anxiety and
Psychiatry 1991;158:676-84.

8 Goodyer IM, Wright C, Altham PME. Recent achievements and adversities in anxious and depressed school-age children. 7 Child Psychol Psychiatry 1990; 31:1063-77.

9 Goodyer IM, Wright C, Altham PME. Maternal adversity and recent stressful life events in anxious and depressed school-age children. 7 Child Psychol
lodyer Psychiatry 1988;29:651-68.

10 Rutter M. Psychosocial resilience and protective mechanisms. In: Rolfe J, Masten AS, Cicchetti D, Nuechterlein K, Weintraub S, eds. Risk and protective factors in the development of psychopathology. Cambridge: Cambridge University Press, 1990:181-214.

11 Goodyer IM. Risk and protective processes in development. In: Spencer N Lindstrom B, eds. European textbook of social paediatrics. Oxford: Oxford University Press, 1992 (in press).

12 Rutter $M$. Resilience in the face of adversity: protective factors and resistance to psychiatric disorder. Br f Psychiatry 1985; 147:598-611.

13 Padilla ER, Rohsenhow D, Bergman A. Predicting accident frequency in children. Pediatrics 1976;58:223-6.

14 Stein SP, Charles ES. Emotional factors in juvenile diabetes mellitus: experience of eight diabetic children. Psychosom Med 1975;37:237-44.

15 Heisel JS, Ream S, Raitz R, Rappaport M, Coddington D. The significance of life events as contributing factors in the diseases of children. III. A study of life events as contributing factors in the diseases

16 Steinhausen $\mathrm{H}$-C. L. Life events in relation to psychopathology among severely and chronically ill children and adolescents. Child Psvchiatry Hum Dev 1983;13:249-58.

17 Meyer R, Haggerty R. Streptococcal infections in families. Pediatrics 1962;29: $539-49$. 